\title{
A Arqueologia do Cuidado: da \\ Prática ao Discurso ${ }^{1}$
}

\author{
Sidi Askofare ${ }^{2}$ \\ Universidade de Toulouse II - Le Mirail
}

\begin{abstract}
A noção de cuidado, assimilada há muito tempo ao tratamento e, então, ao conceito de terapêutica, retorna, logo depois, nos estudos, pesquisas e reflexõesnas ciências humanas. Mas, daí em diante, está emancipado de suas aderências e conotações médicas por serem demasiadamente redutoras. $O$ presente artigo propõe uma arqueologia (no sentido foucaultiano) do cuidado - de suas origens animais às suas formas culturalmente e historicamente definidas - e põe em evidência a subversão que produz. no campo do cuidado - das práticas aos discursos - a emergência e a dominação do discurso da ciência.
\end{abstract}

Descritores: Cuidado. Medicina. Psicologia clínica. Discurso científico.

$A_{\text {doxicomania é inconsistente ou a toxicomania não existe: são enuncia- }}^{\text {tondensam uma perspectiva absolutamente apaixonante sobre }}$ a toxicomania, encontrando seu limite na existência - mas, desta vez, no sentido ingênuo e trivial do termo - dos toxicômanos. Os diferentes discursos - jurídico, médico, psicológico, psicanalítico, educacional etc. -, e as práticas profissionais que suscitam, atestam, suficientemente, para que não tenhamos necessidade de nos demorar aí.

Sabe-se que a inconsistência da toxicomania refere-se, ao menos em parte, à diversidade de seu estatuto e de seu conceito, que variam em função do discurso de referência: delito, doença, alcoolismo, imaturidade, sintoma etc.

1 Tradução do texto original: Helena M. S. Bicalho.

2 Psicanalista, Doutor de Estado, Mestre de Conferências, Diretor de Pesquisas, na Universidade de Toulouse II - Le Mirail, 19, rue du Taur, France - 31000. Toulouse. Endereço eletrônico: s.askofare@wanadoo.fr 
Apesar das definições contraditórias e até antagônicas do toxicômano e da toxicomania, parece constituir-se uma certa unanimidade ao redor de um ponto: devemos nos preocupar com a toxicomania - como mal-estar, como sintoma, como calamidade pública etc. -, devemos nos ocupar, preocupar e até cuidar do toxicômano.

Assim, a questão fundamental sobre a toxicomania, aquela que se impõe a cada um, qualquer que seja o discurso sob o regime do qual ele funciona e, portanto, sua ação realça, é a do cuidado. É preciso acrescentar essa questão: com a condição que o cuidado não seja reduzido ao cuidado médico, quer dizer, ao tratamento, à terapêutica, com sua intenção de restituição ad integrum?

O ponto de partida, onde procuraria esboçar os contornos da arqueologia do cuidado, é uma constatação com um brilho que cega: sempre e em todo lugar houve cuidado; essa universalidade do cuidado se duplica de seu caráter não especificamente humano. Desse ponto de vista, poder-se-ia fazer uma "história natural" do cuidado, até sua etologia; antes de ser uma atividade e uma prática humana, o cuidado aparece e pode ser definido, de início, como um comportamento animal forçado pelo instinto. A partir de uma certa escala na evolução animal, a sobrevivência do indivíduo só é possível com a condição de um certo número de cuidados - desde a alimentação até à proteção, passando pelo zelo, o abrigo etc., que lhe são concedidos sem parcimônia.

O cuidado, no sentido genérico, não é específico ao homem e não o particulariza; o que especifica o humano, na problemática do cuidado, é o paradoxo que lhe imprimem duas determinações particulares: a primeira diz respeito à prematuração específica do nascimento - a inacababilidade anatômica do sistema piramidal, a impotência motora, a dependência de uma criação - a partir da qual o pequeno homem exige, para o seu desenvolvimento e sua autonomia, um tempo mais longo de criação e, portanto, de cuidados; a segunda, é que esses cuidados se estendem num espaço, num universo de linguagem com, a mínima,quatro conseqüências importantes.

Essas consequiências são as seguintes: a primeira é a desnaturação do cuidado que deixa de ser instintual para elevar-se à dignidade de uma prática cultural devido à marca de linguagem que recebe; a segunda, ao destacar que esses cuidados ocorrem através da linguagem, submete-os aos efeitos de divisão intra-subjetiva, à dialética intersubjetiva do laço social e à disparidade 


\section{A Arqueologia do Cuidado: da Prática ao Discurso}

subjetiva que impõem a alienação significante ao Outro: o cuidado torna-se não apenas qualquer coisa que se dá, mas, também, qualquer coisa que se pode demandar, recusar, negociar etc.; a terceira ocorre em um nível mais radicalmente social, quer dizer, no plano da Cidade, onde o cuidado se profissionaliza, inicialmente de maneira restrita, para ampliar-se aos poucos até estabilizar-se nas funções sociais mais ou menos eminentes; a quarta mostra que essa prática de cuidado quase nunca se apresenta em um estado de uma prática silenciosa, de um fazer bruto que não preceda, acompanhe ou recupere algum saber. As práticas dos cuidados são sempre tomadas nos saberes, nos discursos que os fundam, justificam, orientam ou esclarecem.

Mas é necessário distinguir os saberes que fundam e justificam as práticas que se ordenam a partir de seus enunciados não-dialetizáveis - quer dizer, em geral, os mitos, os dogmas religiosos ou ideológicos - dos saberes que constituem a elaboração crítica e racional de uma experiência, isto é, de uma prática regrada.

Desse ponto de vista, a história da medicina grega constitui um paradigma, suscetível, ao mesmo tempo, de nos ensinar e orientar nossa reflexão sobre os discursos, as práticas e as formações das toxicomanias.

O exemplo grego é, de qualquer maneira, precioso, na sua contribuição para distinguir a medicina pré-hipocrática da maior parte do que se chama, ainda hoje, de medicinas tradicionais.

Na Grécia como em outros lugares - na Mesopotânia, no Egito, na Índia, na China ou em qualquer outra parte - a Medicina era, inicialmente, uma prática mágica, depois religiosa ou mágica-religiosa, cujo exercício era direito dos xamãs ou das famílias de sacerdotes, de exorcistas ou de profetas.Quando a articulação orgânica dessas práticas com as concepções de mundo de seus diferentes povos foi conhecida, pôde-se demandar por que e como - por qual "milagre" - a medicina grega libertou-se da magia da religião para constituir uma medicina clínica tradicional.

Não há, evidentemente, um milagre, na medida que as razões dessa exceção grega estão, atualmente, plenamente estabelecidas. Elas sustentam, em suma, quatro determinações: a primeira é a especificidade da religião dos Gregos, que não teria ortodoxia, dogma, um sistema de recusa de toda crítica 
das idéias e das práticas existentes e de toda inovação. "Certamente, há crenças profundamente enraizadas e muito difundidas, mas não há o livro sagrado comum a todos os Gregos, não há a religião 'verdadeira' e única, com as representações universalmente reconhecidas (sacerdotes ou profetas), apoiada por uma autoridade religiosa organizada - uma Igreja" (Lloyd, 1990, pp. 28-29); a segunda é a emergência da Filosofia, especialmente sob a forma particular de uma Filosofia da Natureza, de uma investigação sobre a Natureza, quer dizer, de uma Física; a terceira é a democracia como forma de governo, mas, sobretudo como cultura política da disputa, da controvérsia, da argumentação, da deliberação e da razão da maioria dos homens; a quarta é a sofística, com o nascimento de um novo tipo de professor, por profissão, que ensinaria por dinheiro, não importa qual ciência ou arte, cuja especialidade verdadeira permanece a retórica.

É sobre o fundo da crítica racional das crenças e dos costumes religiosos feita pelos filósofos - no sentido primeiro - que surge e, depois, é desenvolvida, a crítica das noções mágicas que constituiriam os próprios fundamentos da antiga medicina. Naquilo que se chama, tradicionalmente, o corpus hipocrático verdadeiro (defesa e ilustração) da nova medicina racional, o texto que ocupa uma posição essencial é o tratado intitulado Da Medicina Sagrada.

Esse texto, absolutamente extraordinário, chega a atingir, graças a uma crítica assídua das teses dominantes, naquela época, sobre a epilepsia, dois objetivos importantes: o primeiro estabelece que a suposta "doença sagrada" não é "mais sagrada que qualquer outra doença" e que ela tem, como todas as outras doenças, uma causa natural - quer dizer, que os deuses não intervêm como causa dessa doença; o segundo denuncia como impostores aqueles que pretendem curar a epilepsia com os meios mágicos ou religiosos: purificações, feitiços etc.

O autor chega mesmo a propor a seguinte explicação para a epilepsia, que era considerada como uma "doença sagrada":

aqueles que, os primeiros, santificaram essa doença, foram o que me parecem ser hoje os magos (sacerdotes da religião dos antigos persas), os penitentes, os charlatães, os impostores, todas as pessoas que aparentam piedade e ciência superior. Lançando, então, a divindade como uma capa e um pretexto que abrigasse a impotência delas para procurar coisas que fossem úteis, essas pessoas, para que 


\section{A Arqueologia do Cuidado: da Prática ao Discurso}

a ignorância delas não se tornasse manifesta, pretendiam que essa doença fosse sagrada. Com a ajuda de raciocínios apropriados, arranjam um tratamento no qual tudo era certo para eles, prescrevendo expiações e feitiços, defendendo os banhos e alimentos diversos, pouco convenientes às doenças. (Lloyd, 1990, p. 127)

A virada é, assim, alcançada e vai conduzir a Medicina a se separar da tutela das representações mágico-religiosas para orientação, a partir de uma racionalidade fundada sobre a experiência clínica, da fisiologia e da anatomia nascentes.

Mas a questão que nos interessa, verdadeiramente, é a seguinte: quais são os agentes dessa nova prática médica? Quem está habilitado a cuidar, a exercer, a elaborar e a falar dessa medicina? Quais são os discursos e as práticas? Qual é a transmissão e a formação?

Os historiadores da Grécia Antiga concordam em destacar a ambigüidade do estatuto do médico nos séculos IV e V: mesmo se havia quaisquer práticos que exerciam a Medicina em tempo integral, ela não era uma profissão no sentido que a entendemos hoje. Llyod (1990) apresenta o seguinte argumento:

as qualificações profissionais daqueles que praticavam não eram reconhecidas legalmente, não importava quem pretendesse cuidar dos doentes. Portanto, veremos o autor do tratado Sobre a doença antiga, por exemplo, insistir sobre a distinção entre o médico, que tem a experiência da "arte", e o simples profano (idiotas); ao mesmo tempo, o tratado Sobre a doença sagrada, destaca a diferença que separa o representante verdadeiro da arte médica e o charlatão. Em geral, os conhecimentos e as atitudes técnicas se transmitem, em medicina, como nas outras artes e ofícios, por meio de um sistema análogo ao da aprendizagem, no qual os jovens - freqüentemente, mas não exclusivamente, os filhos de médicos - recebiam o ensino daqueles que praticavam e já estavam estabelecidos. Desde o fim do século VI, certas cidades, como Crotone e Cyrene, eram célebres por seus médicos, e no século V, desenvolveu-se, ao mesmo tempo, em Cós (a cidade natal de Hipócrates) e Cnide, em especial, prósperas escolas de medicina, no duplo sentido da palavra "escola": as cidades tornam-se os centros principais de ensino de medicina, e os médicos associados a uma ou outra teriam em comum certas doutrinas e práticas médicas. (pp. 66-67)

Assim, ficam esboçados os elementos que foram determinantes para o surgimento e desenvolvimento da medicina moderna. Essa medicina só pôde se constituir a partir da crítica e da recusa das representações mágicas e religio- 
sas da doença; a constituição de um corpus clínico, de uma coleção de casos (casuística) fundada sobre uma observação metódica; o apelo a um saber positivo racional sobre o corpo, sua anatomia e fisiologia; a elaboração progressiva de um sistema etiológico, diagnóstico, terapêutico e prognóstico informado pelo saber saído da investigação sobre a natureza (o corpo vivo).

Pode-se, assim, afirmar que as consequiências do surgimento dessa medicina grega são ao menos de duas ordens: a primeira denominarei de $n a$ turalização da doença, cuja questão essencial é a mudança no conceito de causalidade; a segunda é a laicização do cuidado: a aptidão dispensada aos cuidados não é mais concebida como um dom ou um atributo consubstancial a uma pessoa ou descendência. Cuida-se, não com o que se é, mas com a arte, o método e o saber.

Para concluir, acrescentarei mais um ponto: se a dimensão epistêmica foi essencial nessa virada grega, observa-se, no entanto, que essa medicina e, em consequiência, toda medicina e toda clínica digna desse nome, jamais se confundirá com a ciência.

Para os gregos, a Medicina jamais será episteme; ela permanecerá sempre uma técnica, quer dizer, uma arte no sentido das "artes liberais", mas uma técnica que impregna, que orienta e que alimenta a episteme. Dessa maneira, ela não saberia se transmitir nem como as artes e ofícios que são, quase exclusivamente, habilidades, nem como as ciências formais (matemática, lógica) ou as ciências da natureza cuja discursividade ou formalização opera com um modo de transmissão que não exige, daquele que ensina, a prática de qualquer técnica.

Sócrates e, mais radicalmente, Platão, que sistematizou a crítica de seu mestre acerca dos Sofistas, revelaram a impostura fundamental e a inconsequiência em ensinar uma técnica da qual não se tem prática. Finalmente, a posição dos Gregos é que um homem que não exerce a arte pode, sem dúvida, ensinar as coisas mais úteis com sua competência em fisiologia, anatomia, matemática etc. - mas a arte médica só poderia ser transmitida por aquele que a pratica.

Esse desvio pelos Gregos antigos, certamente, preparou uma maneira de introduzir a problemática da articulação das práticas, dos discursos e das formações na área clínica em geral e, em particular, na área de psicologia clí- 


\section{A Arqueologia do Cuidado: da Prática ao Discurso}

nica. Para isso, precisamos examinar, anteriormente, certos acontecimentos que se produziram depois dos Gregos e dos quais somos herdeiros e tributários assim como, ou mais, da medicina hipocrática e suas reincidências, das quais destacaria duas: o nascimento da ciência moderna no século XVII e seus efeitos no campo da clínica.

Não se pode silenciar, mesmo num sobrevôo rápido sobre essas questões complexas, a diferença entre a ciência grega, que enquadrou a medicina hipocrática e a ciência moderna de Galileu, Descartes e Newton. Entre ambas ocorreu não apenas descontinuidade e ruptura, mas, fundamentalmente, reforma do entendimento e retificação da ética. O surgimento dessa ciência moderna devemos, sem dúvida, aos monoteístas judeus e, particularmente, ao estatuto que eles concedem à letra, segundo Lacan (1990), e aos cristãos, devido ao dogma da encarnação, segundo Kojève (1964), mas também e principalmente, à operação cartesiana do Cogito, de onde saiu o sujeito da ciência.

Assim, a Medicina, contemporânea dessa figura da ciência, será também diferente da medicina hipocrática.

É possível declinar quatro consequiências interessantes para o propósito desse trabalho: a primeira é o nascimento de uma medicina experimental e de indústrias ligadas aos cuidados; a segunda é a formação do médico com tendência a sacrificar a arte médica, a relação clínica em proveito da formação científica e técnica; a terceira é a especialização cada vez maior dos médicos, em consequiência de progressos fulgurantes dos conhecimentos e do conjunto dos aparelhos e acessórios diversos disponíveis para essa finalidade; a quarta é a cisão e até o conflito entre pesquisa fundamental e pesquisa clínica. Decorrem daí os problemas relativos à formação dos médicos e de suas identidades profissionais, que também pode se estender aos psicólogos.

Um outro acontecimento maior que nos separa da ciência e da medicina grega é a descoberta do inconsciente e a invenção da Psicanálise.

A Psicanálise, desde Freud, introduz uma reforma da concepção clássica de causalidade. Se os Gregos "naturalizaram" a causalidade rejeitando toda intervenção dos deuses na etiologia das doenças, a Psicanálise introduz a idéia de causalidade psíquica, ou melhor, lógica, causalidade pelo Logos, pela linguagem. 
Essa figura original da causalidade, que atribui sua eficiência à linguagem, articula-se a uma problemática do sujeito, do saber, da verdade e do gozo. Ela nos permite dizer que aquele que fala é o único vivo que é doente, mas que se sabe doente e pode adoecer.

A Psicanálise não descobre, mas esclarece e permite determinar a posição e tratar essa relação, ao mesmo tempo "trivial" e completamente particular, que se instaura especialmente nas relações de cuidado e que Freud denomina transferência.

A essa problemática da transferência, sua análise e solução, a Psicanálise contrastou, muito cedo, a questão da formação do analista, que nunca cessou de preocupar as comunidades psicanalíticas seja por meio dos temas da análise didática, da supervisão ou do fim da análise (o passe).

Finalmente, e não é por pouco mérito, a Psicanálise não apenas elaborou uma teoria inédita do discurso como laço social, mas pôde estabelecer e formalizar o seu laço social específico, que a liberou da tutela e da fascinação da ciência. É essa formalização que dará ao passe e ao desejo do analista o seu verdadeiro fundamento de razão. A partir daí surge uma tese paradoxal que poderia ser formulada da seguinte maneira: o psicanalista se forma, especialmente, por uma "psicanálise didática", mas a própria Psicanálise não se transmite: ela se inventa, é uma questão de estilo, de desejo e de ato.

O domínio da civilização moderna pelo discurso da ciência faz pesar sobre muitas práticas humanas um risco mortal, o de reduzi-las a simples aplicações de um saber formalizado onde não habita nenhum desejo. Se a ciência teve um papel completamente positivo no processo que tornou dominante a transmissão esotérica e extra-familiar do saber, pode-se demandar se ela não atinge seu limite quando procura impor seu modo próprio de transmissão aos technai. Não é que essas práticas não comportem o saber, é que o saber delas não é ensinável por qualquer um, pois busca suas fontes vivas na experiência.

Que não haja prática sem saber deveria conduzir a especificar tal prática: qual é o saber exigido e qual é o saber produzido; que não haja prática sem saber diz que não há verdadeiro que não se ordene num discurso (prática discursiva) ou dentro de um discurso (laço social). Ao mesmo tempo, há a problemática do saber, o tipo de laço social e de desejo no qual o sujeito se 


\section{A Arqueologia do Cuidado: da Prática ao Discurso}

situa, para que possa ocupar a função de agente do discurso. É a prática de um discurso que permite saber sobre sua ética e, então, assegurar uma transmissão conforme a lógica desse discurso.

Askofare, S. (2006). Archeology of the taking-care. Psicologia USP, 17(2), 157-166.

Abstract: The concept of taking-care, included a long ago in the treatement and then to the concept of therapeutics, returns after little time in the studies, researchs and reflexions in the human sciences, But, from now on, it is emancipated from its medical adherences and connotations due to their excessives reductions. The present article proposes an archeology (in the Foucault's sense) of the taking-care- from its animal origin to its cultural and historical forms- and put in evidence the subversion produced in the field of taking-care, from practices to speechs, the emergency and domination of the science discourse.

Index terms: Taking-care. Medical sciences. Clinical psychology. Science discourse.

Askofare, S. (2006). Archéologie du soin. Psicologia USP, 17(2), 157166.

Résumé: La notion de soin,longtemps assimilée au traitement et donc au concept de thérapeutique, fait retour depuis peu dans les études, recherches et réflexions dans les sciences humaines. Mais, désormais, c'est em tant qu'émancipée de ses adhérences et connotations médicales par trop rédutrices. Le présent article propose une archéologie (au sens foucaultien) du soin-de ses origines animales à ses formes culturellement et historiquement définies- et s'attache à mettre en évidence la subversion que produit dans le champ du soin-des pratiques aux discours-l'émergence et la domination du discours de la science.

Mots-clés: Soin. Médicine. Psychologie clinique. Discours de la science. 


\section{Referências}

Kojève, A.(1964). L'origine chrétienne de la science moderne. In A. Koyré, L'aventure de l'esprit (Vol. 2, pp. 265-306). Paris: Hermann.

Lacan, J. (1990). Le séminaire. Livre 7. L'éthique de la psychanalyse. Paris: Flammarion.

Lloyd, E. R. G. (1990). Origines et développement de la science grecque : magie, raison et expérience. Paris: Flammarion.

Recebido em: 20.01.2006

Aceito em: 6.03.2006 